\begin{tabular}{c|c|c}
\hline \hline & MARINE ECOLOGY PROGRESS SERIES \\
Vol. 235: 29-42, 2002 & Mar Ecol Prog Ser & Published June 19 \\
\hline \hline
\end{tabular}

\title{
Fluorescence patches in high-frequency internal waves
}

\author{
Cleridy E. Lennert-Cody ${ }^{1, *}$, Peter J. S. Franks ${ }^{2}$ \\ ${ }^{1}$ Inter-American Tropical Tuna Commission, 8604 La Jolla Shores Drive, La Jolla, California 92037-1508, USA \\ ${ }^{2}$ Scripps Institution of Oceanography, University of California San Diego, La Jolla, California 92093-0218, USA
}

\begin{abstract}
Phytoplankton patchiness associated with high-frequency internal waves was investigated by analyzing chlorophyll fluorescence along isotherms. In summer, patches of fluorescence were found over wave troughs through the upper part of the water column and occasionally under wave crests deeper down. A similar pattern was observed in spring; day-to-day variability in the vertical structure of fluorescence patchiness was however greater in spring than in summer. Maximum fluorescence within patches was typically less than $130 \%$ of the background fluorescence, ranging from 104 to $168 \%$ in spring and 102 to $153 \%$ in summer. The largest values were generally found along isotherms nearest the surface. The patterns of fluorescence and wave form, with additional data on beam attenuation coefficient, were used to test hypotheses of patch formation mechanisms, including non-photochemical quenching, swimming-gradient induced patchiness, and concentration-gradient induced patchiness. While non-photochemical quenching apparently created patches of fluorescence, the magnitude and pattern of the patches could not be completely accounted for by this dynamic. Much of the patchiness was consistent with increases in biomass driven by swimming of phytoplankton in the divergent wave circulation. The contribution of any mechanism to patch formation depends on the phytoplankton community structure: blooms dominated by dinoflagellates will show patches created by swimming and changes in fluorescence yield, while the non-swimming phytoplankton community will tend to show patches of enhanced fluorescence yield.
\end{abstract}

KEY WORDS: Patchiness $\cdot$ Phytoplankton $\cdot$ Fluorescence $\cdot$ Internal waves Resale or republication not permitted without written consent of the publisher

\section{INTRODUCTION}

Phytoplankton are usually patchy in coastal environments over a wide range of scales; these patches are generated by both behavioral and physiological mechanisms (e.g. Kamykowski 1973, Mackas 1984). Among the most dramatic examples of phytoplankton patchiness, episodic blooms of photoautotrophic dinoflagellates can form near-surface bands, much longer along one axis than the other (e.g. Ryther 1955, Franks 1997). Such spatial heterogeneity, during both bloom and non-bloom conditions, has been attributed to changes in phytoplankton concentration that result from the

\footnotetext{
*E-mail: clennert@iattc.org
}

interaction of swimming (or buoyancy-derived motion) and the convergent and divergent flows associated with internal waves and fronts (e.g. Ryther 1955, Kamykowski 1974, Franks 1997, Lennert-Cody \& Franks 1999). Although recently published data suggest that plankton patchiness associated with internal waves may extend through the water column (Haury et al. 1983, Rogachev et al. 1996, Kushnir et al. 1997, Pineda 1999), observations of slicks at the sea surface dominate our knowledge of the effects of internal waves on patchiness of the plankton, especially in the case of internal wave-induced accumulation of phytoplankton.

When the water column is well stratified, internal waves are commonly observed in coastal waters (Baines 1986). Over a wide range of spatial and tempo- 
ral scales, strong correlations between temperature and subsurface chlorophyll fluorescence have been observed for data analyzed in a fixed-depth reference frame (e.g. Denman 1976, Cullen et al. 1983). However, this patchiness of fluorescence generally has been attributed to vertical advection of vertical gradients in fluorescence by internal waves rather than localized changes in cell concentration. Here we describe the vertical structure of chlorophyll a (chl a) fluorescence patchiness associated with highfrequency ( $\geq 2$ cycles $\mathrm{h}^{-1}$ ) internal waves from data collected during spring and summer at a southern California coastal site. To quantify the intensity of this patchiness, and to remove the effect of vertical advection of vertical gradients, the fluorescence was analyzed along isotherms. We use these data to test hypotheses of several patch formation mechanisms including nonphotochemical quenching and swimming. Comparisons of fluorescence and beam attenuation coefficient allow conservative estimates of changes in biomass (vs changes in fluorescence yield), while patterns of patches and wave form allow testing of various swimming models.

\section{MATERIALS AND METHODS}

Data types and collection. Field work was conducted at 2 coastal stations off Mission Beach, California, during the spring and summer of 1997 and 1 day (14 August) in the summer of 1996. One station was in 16 $\mathrm{m}$ of water $\left(\sim 1 \mathrm{~km}\right.$ from shore, $32^{\circ} 46.225^{\prime} \mathrm{N}$, $117^{\circ} 15.984^{\prime} \mathrm{W}$, '16 $\mathrm{m} \mathrm{Stn}$ ) and the other in $30 \mathrm{~m}$ of water $\left(\sim 2.5 \mathrm{~km}\right.$ from shore, $32^{\circ} 46.154 \mathrm{~N}$, $117^{\circ} 16.925^{\prime} \mathrm{W}_{\text {; }} 30 \mathrm{~m} \mathrm{Stn}$ '). In March 1997 sampling was carried out in $27 \mathrm{~m}$ of water $\left(32^{\circ} 46.164^{\prime} \mathrm{N}\right.$, $\left.117^{\circ} 16.778^{\prime} \mathrm{W}\right)$, approximately $250 \mathrm{~m}$ inshore of the $30 \mathrm{~m}$ Stn. Because of the proximity of this site to the 30 $\mathrm{m}$ Stn, the two will be referred to collectively as the 30 $\mathrm{m}$ Stn. Data were available for analysis from a total of $17 \mathrm{~d}$ : $7 \mathrm{~d}$ in spring at the $30 \mathrm{~m}$ Stn between 10 March and 1 May, $5 \mathrm{~d}$ in summer at the $16 \mathrm{~m}$ Stn between 16 July and 5 September, and 5 in summer at the $30 \mathrm{~m} \mathrm{Stn}$ between the 12 August and 19 October (for details see Lennert-Cody 1999). Sampling between April 13 and May 1 occurred during spring blooms of dinoflagellates; water samples collected within the upper $5 \mathrm{~m}$ showed a dominance among phytoplankton $>20 \mu \mathrm{m}$ in size of Lingulodinium polyedrum, with lesser concentrations of Prorocentrum spp. and Ceratium spp. (Lennert-Cody 1999). All sampling was carried out from a small skiff (5 m Boston Whaler), starting in the morning, typically around 09:00 h, and lasting from 2 to $7 \mathrm{~h}$, depending on wind and swell conditions. In general the weather was calm and overcast in the morning, often clearing to partially cloudy or sunny by early afternoon.

Temperature, conductivity, pressure, chlorophyll fluorescence and beam attenuation coefficient ('beam c') were measured by profiling with a small instrument package (CTD). The CTD contained a Sea Bird SBE 19-03, a WETStar miniature fluorometer and a Sea Tech transmissometer (660 nm light source). The CTD was equipped with a small pump so that measurements of conductivity and fluorescence were based on pumped flow. The sampling rate for all instruments was 1 sample per $0.5 \mathrm{~s}$, resulting in approximately 0.5 $\mathrm{m}$ vertical sampling resolution. Factory calibrations were used for all instruments; factory calibration of the fluorometer was performed with known concentrations of coproporphyrin tetramethyl ester. Chlorophyll fluorescence was offset from pressure by $6 \mathrm{~s}$ to account for the tubing in the CTD set-up. The between-cast time interval was approximately $40 \mathrm{~s}$ (16 m Stn) and $1 \mathrm{~min}$ (30 $\mathrm{m} \mathrm{Stn),} \mathrm{respectively.} \mathrm{Profiling} \mathrm{with} \mathrm{the} \mathrm{CTD}$ was done by allowing the instrument package to freefall to within several $\mathrm{m}$ of the bottom, at an average descent rate of $1 \mathrm{~m} \mathrm{~s}^{-1}$, and then raising it to the surface using a small gasoline-powered gypsy winch. Additional information on site characteristics, as well as detailed discussion of beam attenuation coefficient data, can be found in Lennert-Cody (1999). Detailed descriptions of the physical (e.g. LaFond 1965, Winant \& Olson 1976, Lerczak 2000) and biological (e.g. Allen 1941, Kamykowski 1973, Goodman et al. 1984) environments at this study site are also available elsewhere.

Data analysis. Data processing: High-frequency internal waves were identified from measurements of temperature at depth. Based on results of previous studies in this area (LaFond 1962, Winant \& Olson 1976), 'high-frequency' internal waves were defined as waves with periods $\leq 30 \mathrm{~min}$. Because density has been found by others to be largely dependent on temperature in this general area (Winant \& Bratkovich 1981, J. Lerczak pers. comm.) and because high-frequency variability in our measurements of density was not always considered to be physically meaningful due to an apparent response-time mismatch between temperature and conductivity sensors, temperature was used as a proxy for density. Depth was defined as distance below the surface (i.e. negative downwards). In this coordinate system, a deepening of the isotherms corresponds to a larger negative value for isotherm depth. High-frequency variation in the depth of the isotherms was taken as an indicator of the presence of high-frequency internal waves.

Patchiness of chlorophyll fluorescence was analyzed along isotherms. Chlorophyll fluorescence, reported as chlorophyll concentration in $\mu \mathrm{g}^{-1}$, was used as a proxy 
for the concentration of phytoplankton (but see 'Discussion'). Although sometimes problematic, chlorophyll fluorescence has been shown to be positively correlated with the concentration of chlorophyll (e.g. Falkowski \& Kiefer 1985, Cullen et al. 1997).

To avoid misinterpretation of vertical advection of vertical gradients in fluorescence as localized changes in fluorescence concentration, we analyze fluorescence along isotherms instead of in a fixed-depth reference frame. For each downcast, estimates of alongisotherm fluorescence and isotherm depth were computed as the medians of fluorescence and depth values within given temperature ranges (upcast data were excluded). On each sampling day, only temperature ranges for which data were available over the entire sampling period were used. Isotherms were defined as temperature ranges of 0.25 to $1^{\circ} \mathrm{C}$, depending on the vertical resolution of temperature. Because the time interval between casts varied slightly, alongisotherm fluorescence and isotherm depth data were interpolated to a regular sampling interval (16 m Stn: $40 \mathrm{~s}, 30 \mathrm{~m}$ Stn: $1 \mathrm{~min}$ ) before further processing.

Vertical structure of the relationship between fluorescence patchiness and waves: To characterize highfrequency motions of the isotherms, the vertical structure of high-frequency variations in isotherm depth was described using principal components analysis (Seber 1984) performed on time series of residual isotherm depths. These residuals were computed for each isotherm as the difference in the observed isotherm depth and an estimate of 'background' isotherm depth, obtained by applying a Fourier-domain filter (Press et al. 1989) to the observed isotherm depth to remove variability at periods $\leq 30 \mathrm{~min}$.

Covariation in along-isotherm fluorescence and isotherm depth was summarized using standard spectral techniques (Brockwell \& Davis 1987). The interpolated data were first detrended, then tapered with a split cosine bell taper prior to computing the discrete Fourier transform. The periodograms, cospectra and quadrature spectra were each smoothed with a 5-point moving average. Approximate $95 \%$ confidence intervals for the spectra were computed from the equivalent degrees of freedom and quantiles of the chi-square distribution.

To determine if there was a phytoplankton response to high-frequency internal wave forcing, we looked for relationships that were consistent across isotherms and across sampling dates. Following model predictions (Franks 1997, Lamb 1997, Lennert-Cody \& Franks 1999) and observations (Ryther 1955, Zeldis \& Jillett 1982, Shanks 1983, Franks 1997, Pineda 1999) indicating high plankton concentrations over wave troughs, we focused on the phase $(\varphi)$ of the relationship between along-isotherm fluorescence and isotherm depth. Estimates of $\varphi$ for each isotherm were summarized by the median phase, $\widetilde{\varphi}$, computed over frequencies $\left\{\omega_{i}\right\}_{i=1, \ldots, n}$ corresponding to periods of 5 to $30 \mathrm{~min}$ for which the squared coherency was significantly greater than zero (1-tailed test, $5 \%$ level$_{\text {; }}$ values $\geq 0.53$ ). A 5 min cut-off was selected as this was larger than the estimated buoyancy frequency (shortest possible wave period) (LaFond 1965, Lennert-Cody 1999). The median absolute deviation from the median (m.a.d.; Rice 1988) was computed for each isotherm as a measure of the variability of $\hat{\varphi}\left(\omega_{i}\right)$ about $\tilde{\varphi}$. In computing the m.a.d. as a measure of variability, it was assumed that the variance of a given $\hat{\varphi}\left(\omega_{i}\right)$ was small compared to the variability in $\hat{\varphi}\left(\omega_{i}\right)$ over $\left\{\omega_{i}\right\}_{i=1, \ldots, n}$.

The vertical structure of the absolute value of the phase relationship $\tilde{\varphi}$ was summarized using generalized additive model techniques (Hastie \& Tibshirani 1991). The model fitted was

$$
|\tilde{\varphi}|=\text { overall constant }+ \text { day effect }+ \text { smooth }(\text { depth })+\text { error }
$$

where smooth(depth) refers to a nonlinear depth contribution fitted using a locally-weighted running line (Cleveland 1979; smoothing parameter of 0.75). error refers to an overall Gaussian error distribution, combined with additional individual weights intended to give more influence to values of $|\tilde{\varphi}|$ that were based on more frequencies and/or had smaller m.a.d. These additional weights were computed as the proportion of frequencies used to compute $\tilde{\varphi}$, divided by the m.a.d.

Following the results of the phase analysis, we computed the proportional increase in fluorescence in clearly defined fluorescence patches associated with wave troughs to describe the magnitude of internal wave-induced fluorescence patchiness. We used data for dates where there was a clear indication of a relationship between fluorescence and high-frequency internal waves in the upper water column (30 m Stn: 14 March, 15 to 19 April, 12 and 19 August, and 4 September; $16 \mathrm{~m}$ Stn: 16 July and 5 September) (see 'Results' below). The magnitude of changes of fluorescence was determined from time series of high-frequency along-isotherm fluorescence residuals for each isotherm, obtained in an identical manner to that for isotherm depth. In clearly identifiable waves (waves with displacement amplitudes in excess of the 0.15 sample quantile of residual isotherm depth [ 1 SD]), we computed the proportional increase in fluorescence patches as the maximum fluorescence residual within the wave trough divided by the estimate of the background fluorescence. A fluorescence patch represents an increase in fluorescence over the wave trough that is in excess of both the manufacturer estimate of instrument error $\left(0.01 \mu \mathrm{g} \mathrm{l}^{-1}\right)$ and the 0.15 sample quantile of fluorescence residuals $(\sim 1 \mathrm{SD})$. We will refer to this 
scaled increase in fluorescence as the 'maximum relative fluorescence'. A maximum relative fluorescence value of 1.0 indicates that the maximum within a patch is twice the background fluorescence, while a value of 0.3 indicates that the maximum within a patch is $130 \%$ the background fluorescence.

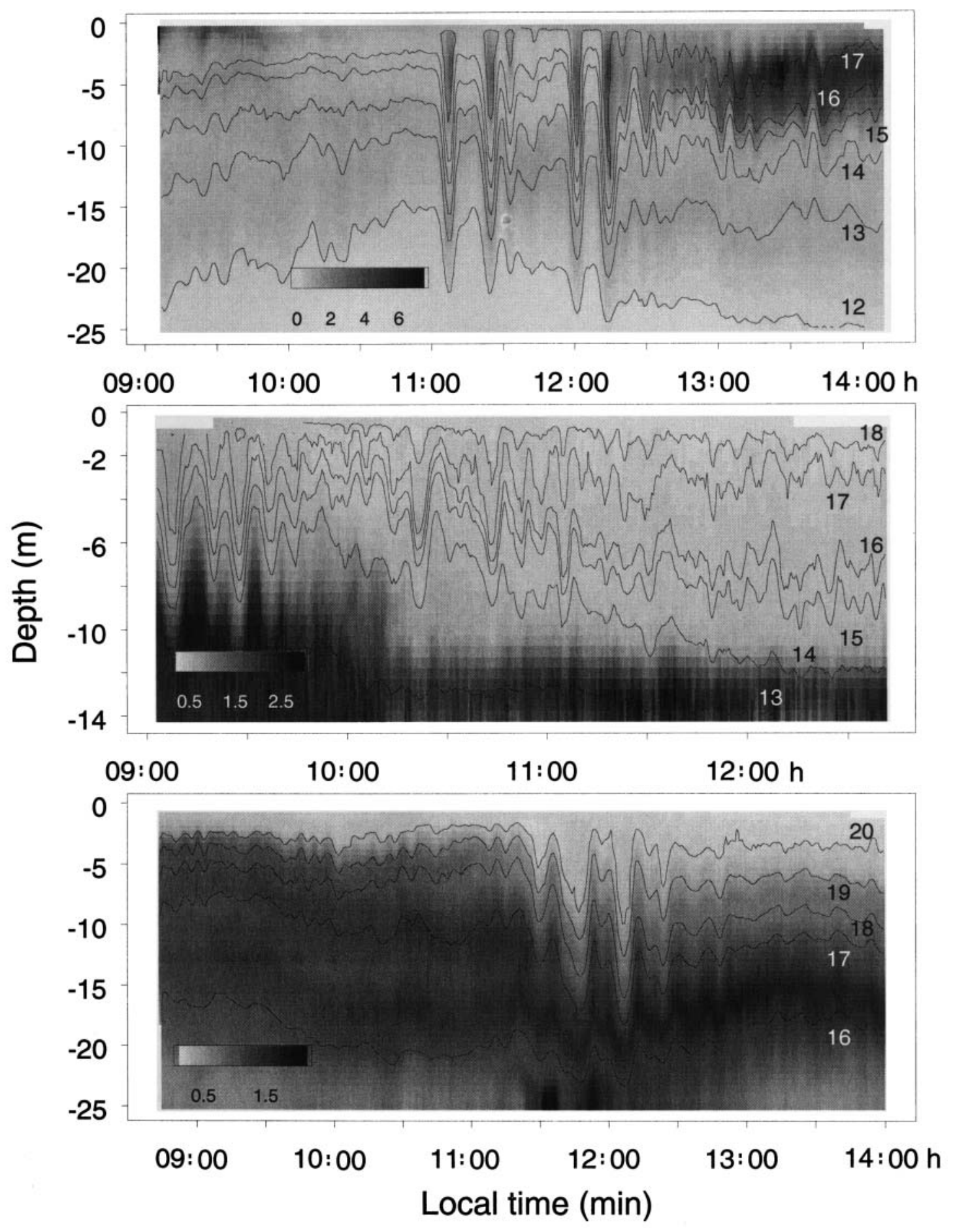

Fig. 1. Fluorescence (grayscale, $\mu \mathrm{g}^{-1}$ ) and temperature (contours, $\left.{ }^{\circ} \mathrm{C}\right)$ for $17 \mathrm{Apr}(30 \mathrm{~m} \mathrm{Stn;} \mathrm{top),} 16 \mathrm{Jul}$ (16 m Stn; middle) and $12 \mathrm{Aug}(30 \mathrm{~m} \mathrm{Stn}$; bottom). Fluorescence and temperature data were interpolated to a regular grid of $0.5 \mathrm{~m}$ by $30 \mathrm{~s}$ (16 m Stn) or $1 \mathrm{~min}(30 \mathrm{~m} \mathrm{Stn})$ using linear interpolation for the purposes of constructing these images 

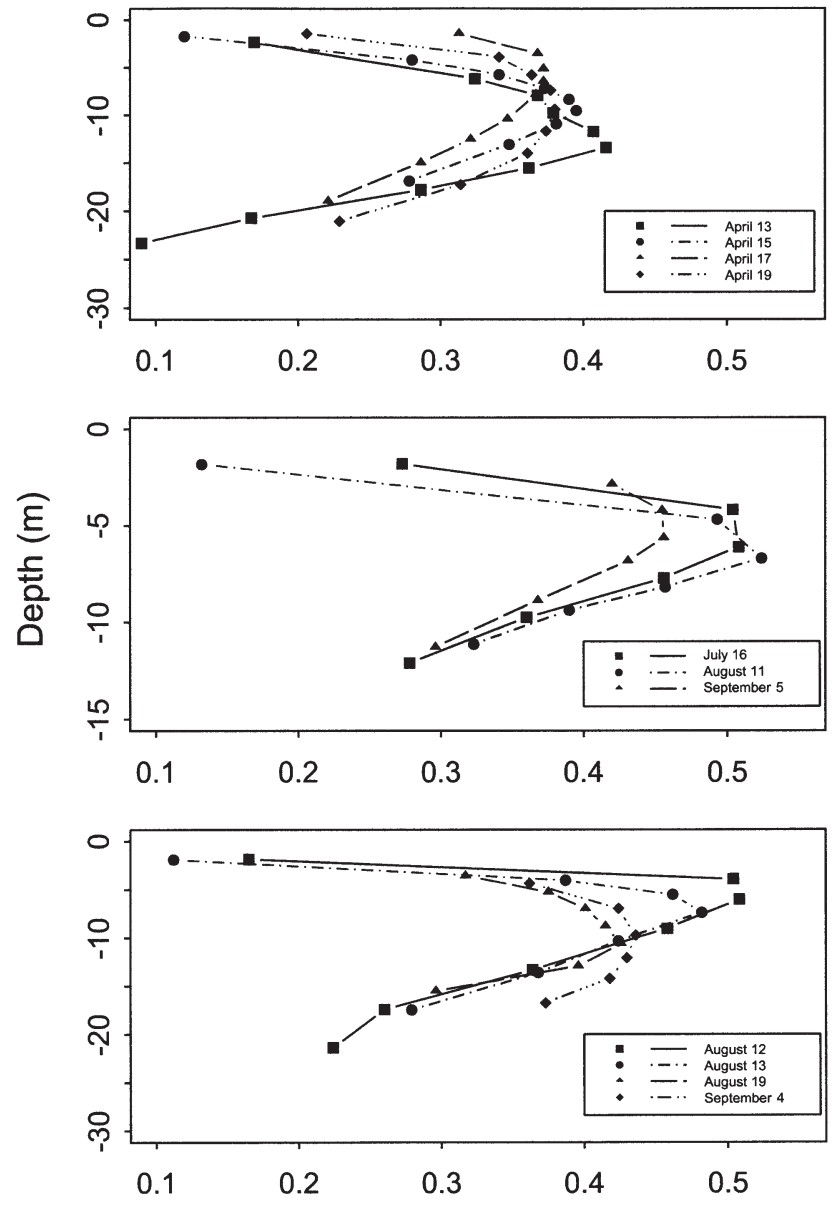

Amplitude of eigenvector

Fig. 2. Amplitude of the eigenvector corresponding to the first principal component of residual isotherm depth for several dates in spring at the $30 \mathrm{~m}$ Stn (top), summer at the $16 \mathrm{~m} \mathrm{Stn}$ (middle) and summer at the $30 \mathrm{~m}$ Stn (bottom). Different line types indicate different sampling dates

\section{RESULTS}

The high-frequency vertical motions of the isotherms had a simple structure. High-frequency internal waves with a range of displacement amplitudes were observed in the temperature data during both spring and summer (Fig. 1). Particularly during spring, waves corresponding to large isotherm displacements ( $>10 \%$ of the water depth) were observed. Principal components analysis of residual isotherm depth showed that verti-

Fig. 3. Examples of along-isotherm fluorescence (solid line, $\mu \mathrm{g} \mathrm{l}^{-1}$ ) and isotherm depth (dashed line, in $\mathrm{m}$ on the righthand axes), for several isotherms and sampling dates: (a) 14.0 to $14.5^{\circ} \mathrm{C}, 17 \mathrm{Apr}(30 \mathrm{~m} \mathrm{Stn})$, (b) 15.0 to $16.0^{\circ} \mathrm{C}$, $16 \mathrm{Jul}(16 \mathrm{~m}$ $\mathrm{Stn})$, and (c) 18.0 to $19.0^{\circ} \mathrm{C}, 12 \mathrm{Aug}(30 \mathrm{~m} \mathrm{Stn})$. cal displacements of the isotherms tended to be in the same direction through the sampled part of the water column (Fig. 2), indicating that the high-frequency internal waves were behaving largely as mode 1 waves. The eigenvector structure corresponding to the first principal component of residual isotherm depth consisted of all positive weights, often with a maximum located in the upper part of the water column. The first principal component explained $>85 \%$ of the variance in the data on all but 3 sampling days (April 13, August 19 to 20). On April 13 to 19, and August 12 to September 4 (30 m Stn), and July 16, August 11 and September 5 (16 m Stn), sampled isotherms spanned most of the upper $2 / 3$ of the water column.

Patches of fluorescence were found associated with high-frequency internal waves over a range of wave amplitudes. Overall, in spring fluorescence was typically greatest near the surface, whereas in summer it was often greatest around the mid-water column or closer to the bottom (Fig. 1). Along-isotherm patchiness of fluorescence associated with high-frequency internal waves was observed in both spring and summer, often spanning several isotherms or extending through the upper part of the water column (Fig. 3). Estimated squared coherency between along-isotherm
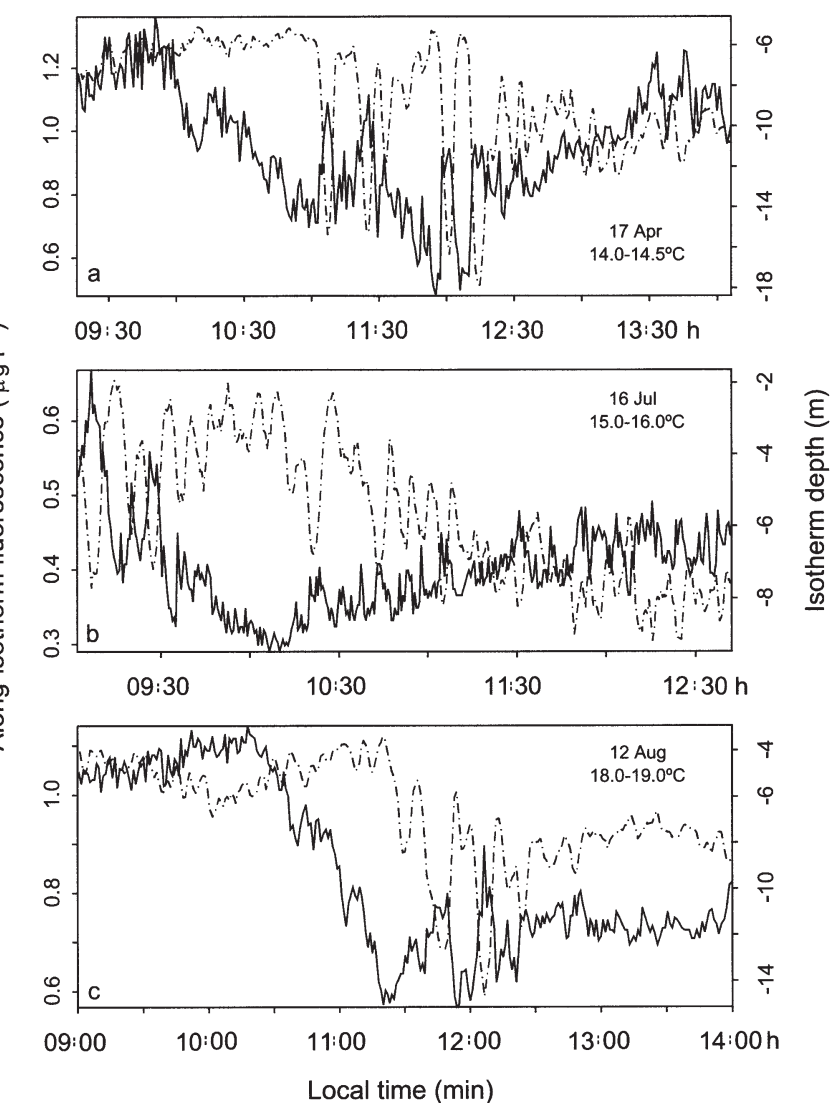

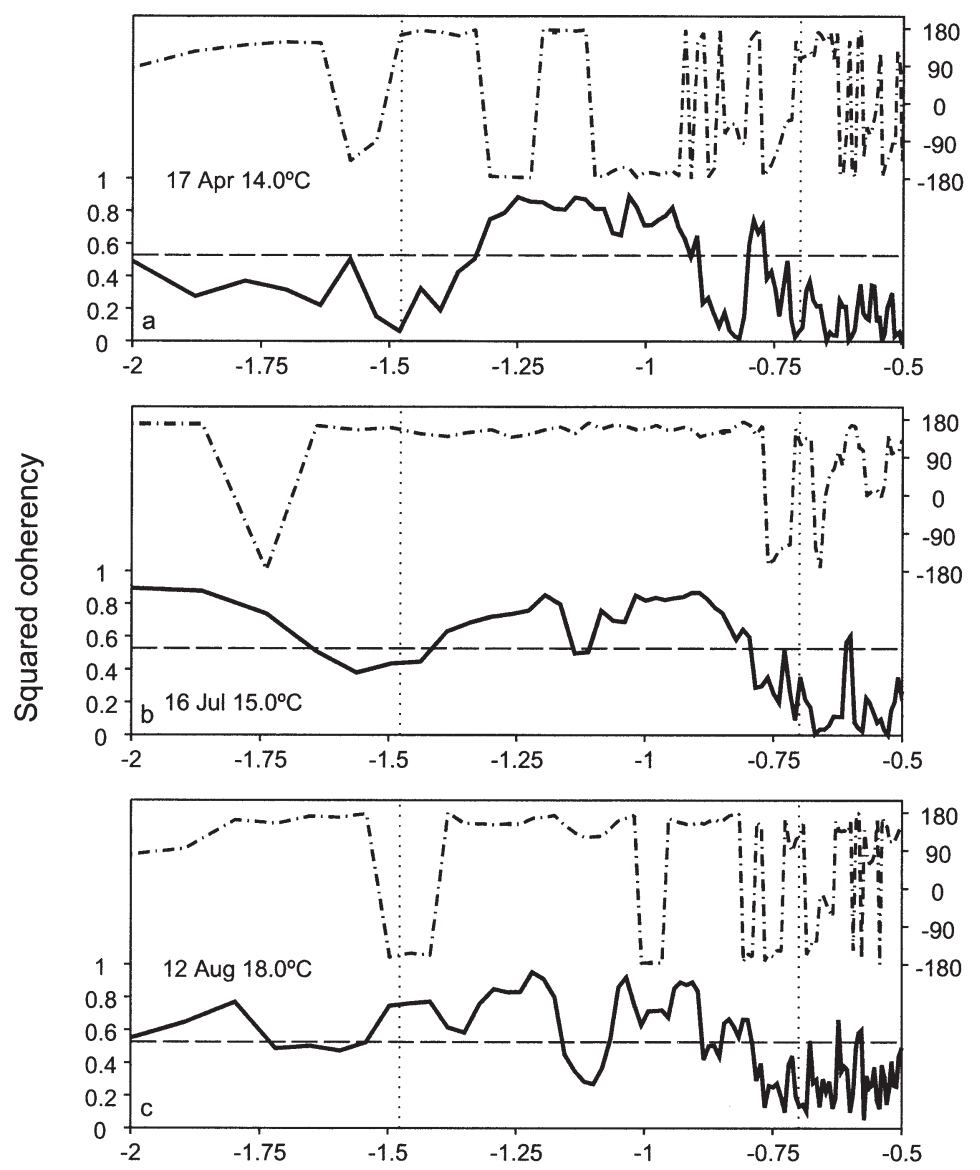

Logarithm of frequency (cycles per minute)

fluorescence and isotherm depth at periods between 5 to 30 min was often as high as 0.8 for some isotherms (Fig. 4). Estimates of phase at periods between 5 to 30 min that were near $\pm 180^{\circ}$ (Fig. 4) indicate the presence of patches of fluorescence over wave troughs (Fig. 3). Patches of fluorescence under wave crests for some isotherms led to estimates of phase near $0^{\circ}$.

This vertical structure of phase was more predictable in summer than spring (Table 1, Fig. 5). Overall, alongisotherm fluorescence and isotherm depth tended to be approximately 'out-of-phase' $\left(|\widetilde{\varphi}|=180^{\circ}\right)$ in the upper part of the water column on some days in spring and most days in summer (Fig. 5). Occasionally this phase relationship changed through the water column and fluorescence and isotherm depth were approximately 'inphase` ( $|\tilde{\varphi}|=0^{\circ}$ ) deeper down (Fig. 5). Strong support for an out-of-phase relationship within part of the upper water column is shown on 14 March, 17 April, 16 July, 12 August and 5 September. Weaker support is suggested on 15 April, 19 April, 11 August, 19 August and 4 September. A change in the phase relationship with depth is suggested on 17 April, 19 April, 11 August, 12 August and 19 August. Day-to-day variability in spring at the $30 \mathrm{~m}$ Stn dominated the relationship between depth and
क
$\Phi$
$\frac{d}{0}$
$\frac{d}{0}$
$\frac{0}{0}$
$\frac{1}{\pi}$
$\frac{c}{0}$

Fig. 4. Estimated squared coherency $\left(K^{2}\right.$; solid line) and phase (dashed line) for along-isotherm fluorescence and isotherm depth for isotherms shown in Fig. 3: (a) 14.0 to $14.5^{\circ} \mathrm{C}, 17 \mathrm{Apr}$, (b) 15.0 to $16.0^{\circ} \mathrm{C}, 16 \mathrm{Jul}$, and (c) 18.0 to $19.0^{\circ} \mathrm{C}, 12 \mathrm{Aug}$. The horizontal black dashed line in each panel shows the upper $95 \%$ confidence bound for a 1tailed test of $\mathrm{H}_{\mathrm{o}}: K^{2}=0$. Periods of 5 and 30 min are shown with dashed vertical lines

phase, whereas in summer, the change in phase with depth was largely consistent across days (Table 1). In summer, greater day-to-day variability in the depth-dependence of phase was found at the $16 \mathrm{~m}$ Stn than at the $30 \mathrm{~m}$ Stn.

Maximum fluorescence within internal wave-associated patches was typically $<130 \%$ of the background fluorescence, especially at the $30 \mathrm{~m}$ Stn in summer. The maximum of fluorescence residuals within patches ranged from 0.04 to $2.57 \mathrm{\mu g} \mathrm{l}^{-1}$ in spring (30 $\mathrm{m} \mathrm{Stn),}$ 0.01 to $0.34 \mu \mathrm{g} \mathrm{l}^{-1}$ at the $16 \mathrm{~m} \mathrm{Stn}$ in summer, and 0.01 to $0.16 \mu \mathrm{g} \mathrm{l}^{-1}$ in summer at the $30 \mathrm{~m}$ Stn (short-term fluorometer error $=0.01 \mu \mathrm{g} \mathrm{l}^{-1}$ ). Maximum relative fluorescence ranged from 0.04 to 0.68 in spring (at $30 \mathrm{~m}$ ), 0.04 to 0.53 in summer at the $16 \mathrm{~m} \mathrm{Stn}$ and 0.02 to 0.32 in summer at the $30 \mathrm{~m}$ Stn. Median values, by isotherm, were typically $<0.3$ at the $30 \mathrm{~m}$ Stn in spring, <0.15 at the $16 \mathrm{~m}$ Stn in summer, and $<0.10$ at the $30 \mathrm{~m}$ Stn in summer. Maxi-

Table 1. Change in deviance and rough $\mathrm{p}$-values for terms in the generalized additive model fit of absolute $\widetilde{\varphi}$ to a day effect and a nonlinear depth term ('smooth(depth)'), by station/season. The change in deviance was computed as the difference in residual deviances for the full model and a model without the term(s) of interest. The degrees of freedom for smooth(depth) are approximate, determined from the amount of smoothing. p-values (for null hypothesis of no effect) are provided only as a rough measure of importance and are based on the assumption that the change in deviance approximately follows a chi-square distribution

\begin{tabular}{|lcr|}
\hline & $\begin{array}{c}\text { Change in deviance } \\
\text { (degrees of freedom) }\end{array}$ & p-value \\
\hline 30 m in spring & $38.9(6)$ & $<0.001$ \\
$\begin{array}{l}\text { Day effect } \\
\text { smooth(depth) }\end{array}$ & $3.8(2.4)$ & 0.200 \\
16 m in summer & $12.8(4)$ & 0.012 \\
$\begin{array}{l}\text { Day effect } \\
\text { smooth(depth) }\end{array}$ & $8.1(2.4)$ & 0.026 \\
30 m in summer & $0.25(4)$ & 0.992 \\
$\begin{array}{l}\text { Day effect } \\
\text { smooth(depth) }\end{array}$ & $14.7(2.6)$ & 0.002 \\
\hline
\end{tabular}



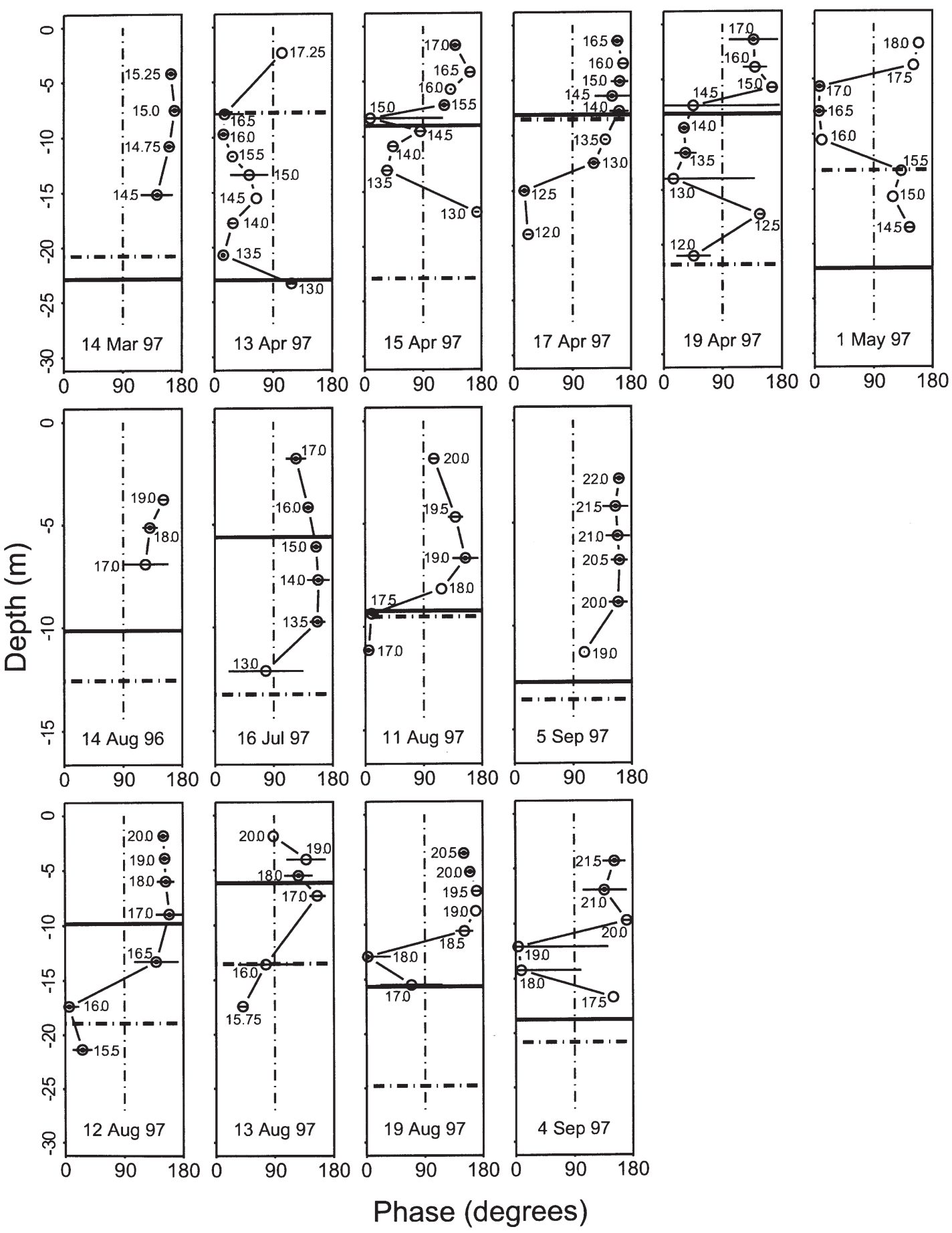

Fig. 5. Absolute value of $\widetilde{\varphi}$ versus the median depth of the isotherm for spring at the $30 \mathrm{~m}$ station (top row), summer at the $16 \mathrm{~m}$ station (middle row) and summer at the $30 \mathrm{~m}$ station (bottom row). The lower temperature bound for each isotherm is shown next to each circle. Filled circles indicate estimates of $\tilde{\varphi}$ that were based on $\geq 20 \%$ of the frequencies corresponding to periods of 5 to 30 min. Maximum depth of the 'pycnocline' obtained by computing the maximum of a smoothed time series of the maximum rate of change of temperature with depth (smoothing parameter of 0.5; Cleveland 1979, Lennert-Cody 1999) is indicated by the thick horizontal black lines. Deepest depth of the maximum fluorescence (computed in an identical manner to the pycnocline) is indicated by thick dashed horizontal black lines. Sampling dates are shown at the bottom of each panel (format: $\mathrm{mm} / \mathrm{dd} / \mathrm{yy}$ ). Data for March 10 and October 9 (30 m station), and August 20 (16 m station), are not shown because all estimates of $\widetilde{\varphi}$ were based on fewer than $20 \%$ of the frequencies corresponding to periods of 5 to $30 \mathrm{~min}$. Horizontal bars indicate \pm m.a.d. (absent when fewer than 2 estimates available). For phase estimates near $0^{\circ}$, the extent of the horizontal bars may be have truncated on the left to show more detail over the interval $0^{\circ}$ to $180^{\circ}$ 


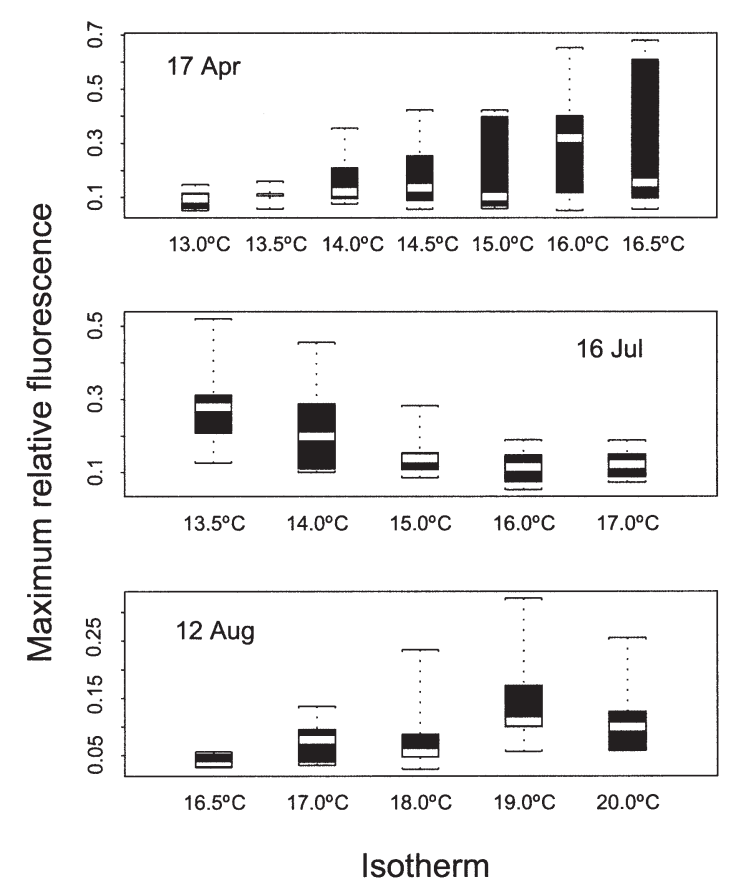

Fig. 6. Boxplots of maximum relative fluorescence within patches over internal wave troughs, by isotherm, for $17 \mathrm{Apr}$ (top panel), 16 Jul (middle panel) and 12 Aug (bottom panel). Isotherms are arranged from coldest (deepest; left) to warmest (shallowest; right). White bars indicate the median, shaded boxes indicate the middle $50 \%$ of the data, and whiskers indicate the full range of the data

mum relative fluorescence tended to be greatest for isotherms nearer to the surface, in both spring and summer at the $30 \mathrm{~m} \mathrm{Stn;} \mathrm{however,} \mathrm{at} \mathrm{the} 16 \mathrm{~m} \mathrm{Stn}$, it was greatest nearer the bottom on July 16 and largely invariant across isotherms on September 5 (Fig. 6).

\section{DISCUSSION}

Data collected in a profiling sampling mode have been used to summarize the relationship between alongisotherm patchiness of fluorescence and high-frequency internal waves at a coastal site. In summer, patches of fluorescence were often found over wave troughs in the upper part of the water column and sometimes below wave crests deeper down (Fig. 5). A similar pattern was seen for some days in spring; however, day-to-day variability in the depth-dependence of the relationship between patches of fluorescence and internal waves was much greater in spring than in summer (Table 1, Fig. 5). Maximum fluorescence within patches was typically $<130 \%$ of the background fluorescence, ranging from 104 to $168 \%$ in spring and 102 to $153 \%$ in summer. The largest increases were often found nearest the surface in both spring and summer (Fig. 6).
We hypothesize that this observed patchiness is due to both behavioral and physiological processes. Because of the time scales involved (periods $\leq 30 \mathrm{~min}$ ), we consider processes such as grazing, growth and senescence to be unlikely mechanisms. Patch-forming processes potentially operating on short time scales include (1) changes in the ratio of fluorescence to chl a (non-photochemical quenching), (2) swimming in internal waves, (3) transport by nonlinear internal waves, and (4) localized internal wave-induced mixing. Mechanism 1 implies a purely physiological response to rapid changes in illumination, whereas mechanisms 2-4 imply that changes in along-isotherm fluorescence are associated with changes in the con-

\section{Along-isotherm fluorescence patchiness}
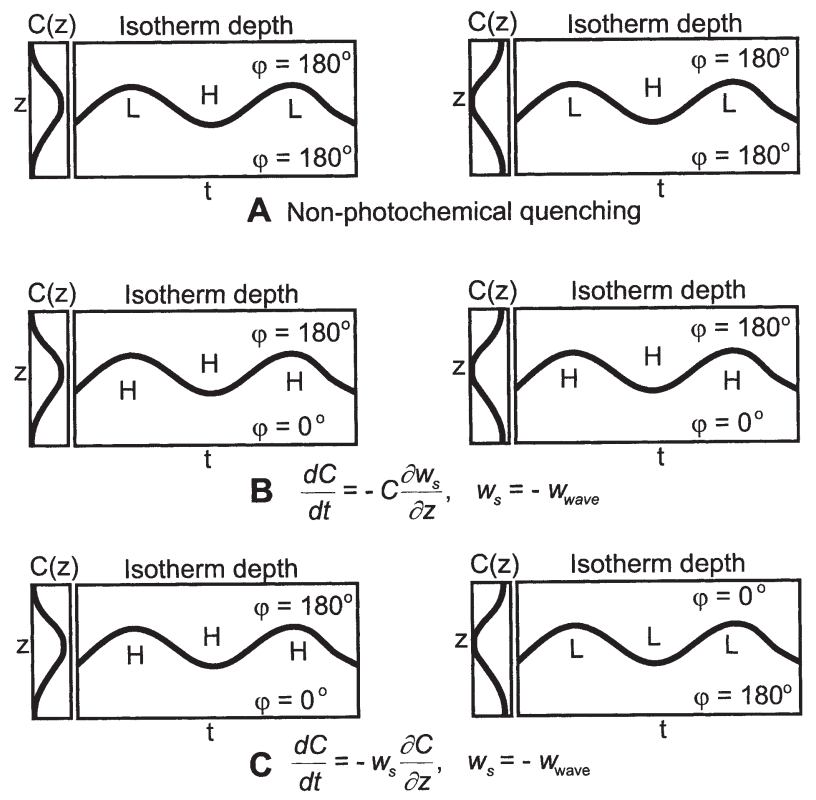

Fig. 7. Illustrations of hypothetical relationships between phytoplankton concentration and the wave form resulting from: (A) non-photochemical quenching, (B) vertical gradients in swimming velocity acting on concentration, and (C) vertical gradients in concentration moved by swimming. To the left of each large panel is shown the background vertical concentration profile $[C(z)]$. ' $\mathrm{H}$ ' indicates high concentration, ' $\mathrm{L}$ ' low concentration. The wave form is indicated by the sinusoidal line within each large panel. The phase relationship between concentration and the wave form, $\varphi$, is also indicated for (A) and (B) with respect to the pycnocline, but for (C) with respect to the concentration maximum. Note that we have defined depth as distance below the surface (i.e. negative downwards). In this coordinate system, a deepening of the pycnocline corresponds to a larger negative value of pycnocline depth. The swimming-induced patterns $(B, C)$ are based on the assumption that swimming is perfectly depth-keeping (i.e. $w_{s}=-W_{\text {waver }}$, where $w_{s}$ is the vertical swimming velocity and $W_{\text {wave }}$ is the vertical wave velocity). However, we note that these swimming-induced patterns also apply with a weakly depth-keeping swimming behavior (i.e. $w_{s}=-\alpha w_{\text {wave }}$ where $-\alpha<1$; see Lennert-Cody \& Franks 1999 for B) 
centration of phytoplankton. We consider mechanisms 1 and 2 in detail, and briefly discuss mechanisms 3 and 4 , below. The predicted patterns of fluorescence/biomass in high-frequency internal waves associated with mechanisms 1 and 2 are shown in Fig. 7. Note that there is at least 1 characteristic (e.g. patches under crests, etc.) that allows distinction among these mechanisms.

\section{Non-photochemical quenching}

Prediction

When phytoplankton adapted to low light are suddenly exposed to high light, the fluorescence yield can decrease rapidly via non-photochemical quenching (e.g. Krause \& Weis 1991), giving an apparent decrease in biomass. In laboratory low-to-high light studies, nonphotochemical quenching resulted in an initial average rate of change in fluorescence of $4 \% \mathrm{~min}^{-1}(\mathrm{SE}=0.8, \mathrm{n}$ = 13) (from graphs and tables in: Kiefer 1973, Sakshaug et al. 1987, Cullen \& Lewis 1988, Demers et al. 1991, Olaizola et al. 1994, Moisan et al. 1998). A sudden change from high light to low light is predicted to give the opposite effect: an apparent increase in biomass with a time scale of minutes. In the field, rapid changes in fluorescence have been attributed to changes in illumination (e.g. Abbott et al. 1982, Stramska \& Dickey 1992, Lizon et al. 1995). In high-frequency internal waves, as the wave moves water downward, nonphotochemical quenching is predicted to cause an apparent increase in biomass, with patches of high fluorescence in the troughs of waves (H in Fig. 7A). Conversely, decreases in fluorescence would be expected under the crests of waves (L in Fig. 7A). Thus, regardless of the underlying vertical distribution of phytoplankton, along isopycnals the wave form and fluorescence should be out of phase throughout the water column (i.e. $|\widetilde{\varphi}|=180^{\circ}$ at the surface and at depth).

Test

To test the non-photochemical quenching hypothesis we explored the phase relationship of fluorescence, beam $\mathrm{C}$, and isotherm depth. Differences between changes in fluorescence (concentration + non-photochemical quenching) and beam c (concentration) will help to quantify the contribution of non-photochemical quenching to the overall signal we measured. While our observations of high-frequency patterns in fluorescence and beam c were not correlated in any statistically meaningful way (Lennert-Cody 1999), large values of beam c were occasionally associated with wave troughs in spring, consistent with measurements of fluorescence (Fig. 8, Lennert-Cody 1999). Much of the signal from the transmissometer is due to scattering from very small particles and cells $\geq 2 \mu \mathrm{m}$ (Stramski \& Kiefer 1991), rather than absorption (Cullen et al. 1997). Large changes in the concentration of large phytoplankton cells may be necessary to obtain a strong signal from the transmissometer, especially in coastal waters, leading to discrepancies between the fluorometer and transmissometer signals. Beam c is thus a conservative measure of changes in cell concentration.

Selecting isotherms closest to the surface (high nonphotochemical quenching) during spring (high concentrations of large motile cells, April 15 to 19; LennertCody 1999) when there was a clear relationship between fluorescence and wave form (Fig. 5), we find a median increase of $7 \%$ for maximum relative beam c (range: $3,21 \%$ ), compared to a median of $35 \%$ (range: $6,61 \%$ ) for maximum relative fluorescence. The median of the ratio of maximum relative beam $\mathrm{c}$ to maximum relative fluorescence by wave was 0.28 (range: 0.10 to 0.62 ). Thus, conservatively, in spring the concentration of phytoplankton increased by $\sim 7 \%$ in wave troughs, with $\sim 28 \%$ of the increase in fluorescence in wave troughs attributable to increased phytoplankton concentration. The remaining increase in fluorescence increase was presumably due to non-photochemical quenching. In summer, non-photochemical quenching might be expected to have the greatest effect, and the greater predictability of the vertical phase structure in summer (Table 1) may reflect the influence of non-photochemical quenching near the surface.
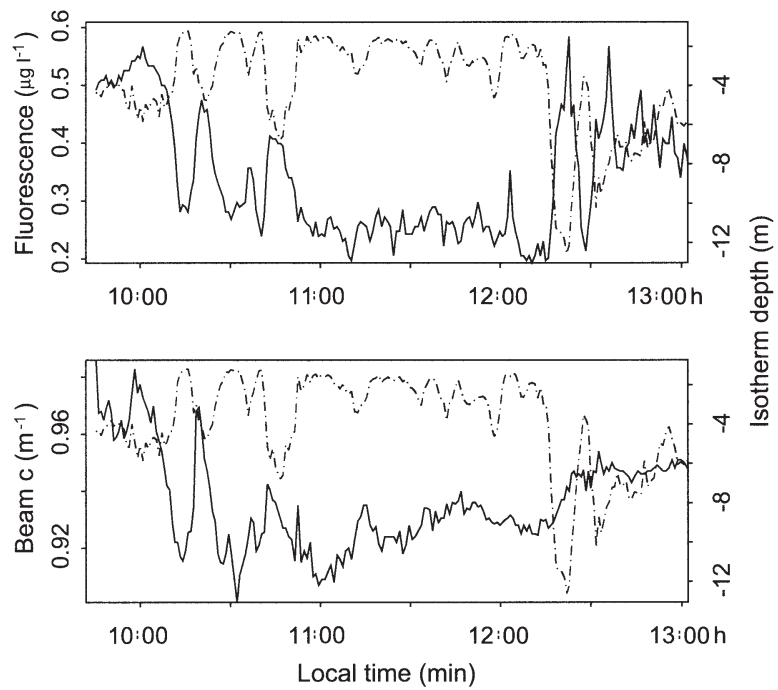

Fig. 8. Along-isotherm fluorescence (solid line in top panel, $\mathrm{\mu}^{-1}$ ) and along-isotherm beam attenuation coefficient (solid line in bottom panel, $\mathrm{m}^{-1}$ ) for $14 \mathrm{Mar}, 15.25$ to $15.50^{\circ} \mathrm{C}$. Isotherm depth is indicated by the dashed line ( $\mathrm{m}$, right-hand axes) 
The average rate of change of fluorescence observed during spring in large waves was $13 \% \mathrm{~min}^{-1}$ (SE = 2.4) - significantly greater than the $4 \% \mathrm{~min}^{-1}$ computed for laboratory studies ( $p<0.01$, Mann-Whitney 2-tailed test), again suggesting that changes in phytoplankton concentration contributed to the observed fluorescence changes. The average rate during summer, although larger, was not significantly different from the laboratory studies $\left(7 \% \mathrm{~min}^{-1}, \mathrm{SE}=1.5 ; \mathrm{p}=\right.$ $0.15)$. It may be significant that laboratory studies of non-photochemical quenching generally show the increasing fluorescence response time to be somewhat longer than the decreasing fluorescence response time (Kiefer 1973, Sakshaug et al. 1987, Demers et al. 1991, Moisan et al. 1998), whereas the changes in fluorescence measured in the field were typically symmetric (same rate of increase and decrease during a wave; Figs. $3 \& 8)$.

\section{Swimming}

To explore the contribution of swimming to changes in fluorescence, we follow Lennert-Cody \& Franks (1999), and assume the concentration of planktonic organisms to be a conservative quantity over the time scales of interest (i.e. no growth or losses) and that the organisms swim only vertically. Under these assumptions, the equation governing temporal and spatial changes in concentration $C(x, z, t)$ in an incompressible fluid following an isotherm is

$$
\frac{\mathrm{d} C}{\mathrm{~d} t}=-C \frac{\partial w_{\mathrm{s}}}{\partial z}-w_{\mathrm{s}} \frac{\partial C}{\partial z}
$$

where $w_{\mathrm{s}}$ is the vertical swimming velocity of the organisms and $d C / d t$ is the local rate of change of concentration plus the advective rate of change of concentration (i.e. the material derivative). In this model, swimming leads to changes in concentration in 2 ways: (1) vertical gradients in swimming velocity acting on concentration (first term on the right-hand-side of Eq. (1), Lennert-Cody \& Franks 1999), and (2) vertical gradients in concentration being moved by swimming (second term on the right-hand-side of Eq. 1). We consider these 2 components below.

\section{Swimming: vertical gradients in swimming velocity}

Prediction. If phytoplankton are weakly depth-keeping (e.g. have a phototactic response) they will interact with the convergences and divergences of the internal wave field to create patches (Franks 1997, LennertCody \& Franks 1999). In a 2-layered ocean (mode 1 waves), patches would be expected over wave troughs above the pycnocline, but under wave crests below the pycnocline (Fig. 7B). This gives a phase relationship between along-isopycnal biomass and isotherm depth of $|\tilde{\varphi}|=180^{\circ}$ above the pycnocline (out-of-phase) and $|\tilde{\varphi}|=0^{\circ}$ (in-phase) below the pycnocline, regardless of the underlying vertical phytoplankton distribution. Note that the pattern of patches under wave crests below the pycnocline is the opposite of the predicted non-photochemical quenching pattern (Fig. 7A,B). To a first approximation, the patch intensity is predicted to be less than twice the background concentration (Lennert-Cody \& Franks 1999).

Test. Principle-components analysis of highfrequency isotherm residuals (Fig. 2) and analyses of the high-frequency velocity structure at this site (Winant \& Olson 1976, Winant \& Bratkovich 1981, Lerczak 2000) suggest that a 2-layered (mode 1) model for the high-frequency internal waves is a reasonable approximation. We found patches of fluorescence over wave troughs in the upper part of the water column, and occasionally below wave crests deeper down (Fig. 5). On several dates (April 17 to 19, August 11 to 12, August 19), the depth of this transition occurred near a rough estimate of the pycnocline depth, consistent with model predictions for swimming gradient induced patchiness. The maximum fluorescence within patches was $<168 \%$ of the background fluorescence, also consistent with changes in concentration driven by gradients in swimming speed.

To further assess model fit to these data, we can obtain a rough estimate of swimming speeds necessary to form patches with a weakly depth-keeping swimming behavior by using the predicted relationship between wave amplitude and changes in fluorescence (Lennert-Cody 1999, Lennert-Cody \& Franks 1999). To a first approximation, the maximum patch intensity is predicted to increase with the wave amplitude at a rate set by the ratio of the swimming speed to the water velocities. Wave velocities were approximated by dividing the wave amplitudes by half the duration of the wave trough. In clearly identifiable waves we obtain rough estimates of swimming speeds of 0.2 to $4.1 \mathrm{~mm} \mathrm{~s}^{-1}$ (Lennert-Cody 1999). Swimming speeds $<1$ $\mathrm{mm} \mathrm{s}^{-1}$ have been reported for dinoflagellates in the literature (e.g. Kamykowski et al. 1992, Kamykowski 1995). The larger swimming speeds estimated here are probably unrealistic, supporting the contention that only a portion of the fluorescence increase can be accounted for by increases in biomass.

Swimming: vertical gradients of concentration

Prediction. If planktonic swimming opposes the vertical wave motion, subsurface concentration gradients 
will move relative to the wave (second term on the right-hand-side of Eq. 1). If swimming is perfectly depth-keeping, the underlying vertical concentration profile will remain stationary in depth while the waves move past it. In the presence of a subsurface concentration maximum, waters moved into the maximum from above (wave trough) or below (wave crest) will show along-isopycnal increases in concentration (Fig. 7C). Thus, with a subsurface maximum, the relation between along-isopycnal concentration and wave form is out-of-phase above the concentration maximum (patches in troughs; $|\tilde{\varphi}|=180^{\circ}$ ), but in-phase below it (patches in crests; $|\tilde{\varphi}|=0^{\circ}$ ). In contrast, with a subsurface concentration minimum, the predicted low concentrations in wave troughs and crests gives $|\tilde{\varphi}|=$ $0^{\circ}$ above the minimum, and $|\tilde{\varphi}|=180^{\circ}$ below it. Note that these predictions are relative to the concentration extrema, not the pycnocline depth as with swimming gradient-induced patchiness (Fig. 7B). If the pycnocline and subsurface maximum coincide, the vertical phase structure will not distinguish swimming gradient-induced patchiness from concentration gradientinduced patchiness (Fig. 7). Also to note is that this mechanism will only work with an underlying concentration gradient; the previous 2 mechanisms will generate along-isopycnal patchiness in fluorescence with a vertically homogeneous concentration profile.

Test. Because of near co-location of the overall fluorescence maximum and the pycnocline on some dates (Fig. 5), we tested the prediction using clearly identifiable wave troughs having intense patches of fluorescence through most of the upper part of the water column, during times with high concentrations of motile phytoplankton (April 15 to 19; Fig. 5). Of the 16 waves meeting these criteria, 8 occurred when there was a subsurface fluorescence maximum. The observed increase in fluorescence was of the same order of magnitude as that predicted from a finite difference approximation to the second term of Eq. (1), after applying a conservative correction for non-photochemical quenching $(7 \%)$. The remaining 8 waves with patches occurred when the vertical fluorescence profile showed a minimum, or was flat, contradicting the concentration gradient-induced patch mechanism. Thirteen of the 16 waves also had patches of beam c, 8 of which formed during conditions when the vertical gradient in beam c was negative over at least part of the water column (Fig. 9) or insignificant with depth, contradicting the concentration gradient induced patchiness hypothesis. In the 5 other waves, observed increases in beam c were 10 to $100 \times$ greater than that predicted by the concentration-gradient-induced patch mechanism. Although results of the above analysis are consistent with concentration gradient induced patchiness for some waves, the occurrence of patches in wave troughs when minima were predicted suggests that the concentration-gradient-induced patch mechanism was not a dominant dynamic in patch formation during these periods.
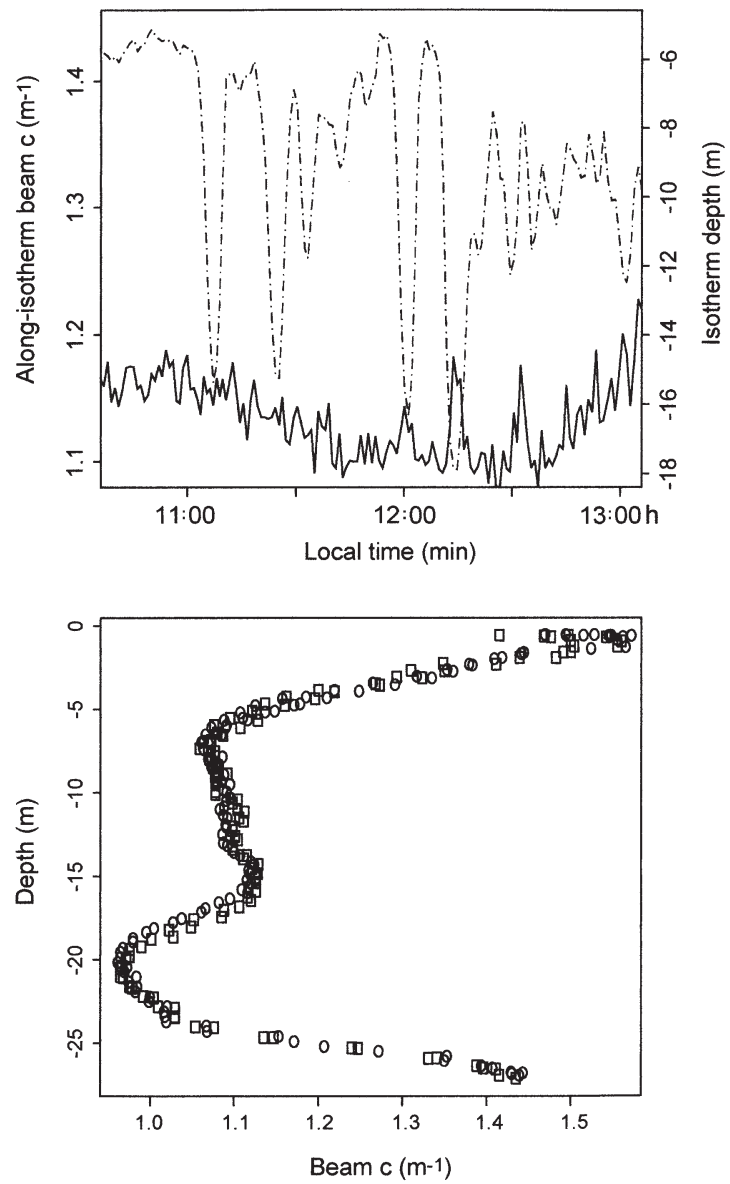

Fig. 9. Top panel: along-isotherm beam c (solid line in $\mathrm{m}^{-1}$ ) and isotherm depth (dashed line in $\mathrm{m}$, right-hand axis) for 17 Apr, 14.0 to $14.5^{\circ} \mathrm{C}$ (see Fig. 3 for along-isotherm fluorescence). Bottom panel: beam c versus depth for casts just ahead of the 2 large waves between 11:50 $\mathrm{h}$ and $12: 20 \mathrm{~h}$ in the top panel. Prior to each wave, the 14.0 to $14.5^{\circ} \mathrm{C}$ starts between 5 and $6 \mathrm{~m}$ depth. For both waves patches in alongisotherm beam c were also present along isotherms closer to the surface, especially for the second wave, where a patch was evident for every isotherm 14.0 to $14.5^{\circ} \mathrm{C}$ and shallower. Given the vertical profiles of beam c ahead of the waves, the 14.0 to $14.5^{\circ} \mathrm{C}$ isotherm is the one most likely to reflect an increase due to concentration-gradient-induced patchiness because of the slight increase in beam c with depth between $\sim 5 \mathrm{~m}$ and $15 \mathrm{~m}$; for shallower isotherms, beam c decreases with depth to below $20 \mathrm{~m}$. However, even for the 14.0 to $14.5^{\circ} \mathrm{C}$ isotherm, we find that the along-isotherm maximum within the wave trough exceeds that ahead of the wave to a depth of at least $20 \mathrm{~m}$, making it unlikely that the observed patchiness was due solely to the concentration-gradientinduced mechanism (first wave: 1.129 ahead of wave versus 1.144 in wave trough; for second wave: 1.124 ahead of wave vs. 1.183 in wave trough) 
From the analyses above we infer that along-isotherm patches of fluorescence associated with highfrequency internal waves were likely formed by combinations of non-photochemical quenching, vertical gradients in swimming speed, and vertical gradients in concentration. The relative contribution of each mechanism (particularly swimming) presumably depended a great deal on the organisms present. Phototaxis, geotaxis (e.g. Kamykowski et al. 1998) and swimming responses to changes in environmental characteristics (Kamykowski 1995) could lead to a weak depth-keeping response in dinoflagellates. Water samples collected in the upper $5 \mathrm{~m}$ during spring showed a dominance of dinoflagellates among the larger phytoplankton (Lennert-Cody 1999); quantitative analysis of summer water samples was not possible. Thus, at least during spring, some unknown fraction of the phytoplankton assemblage was likely motile. We have assumed that the changes in fluorescence and beam $\mathrm{c}$ represent an average population response. If motile phytoplankton were responsible for the observed change in fluorescence, but only accounted for a small fraction of the total fluorescence (or beam c), then we will underestimate the magnitude of the change in their concentration in response to waves.

Patches of fluorescence within large-amplitude high-frequency internal wave troughs might indicate cross-shelf transport by nonlinear internal waves. Rough estimates of the ratio of the eastward ( onshore) currents to the wave's phase speed were generally $\sim 0.4$ to 0.5 for the largest waves observed at the $30 \mathrm{~m}$ Stn (Lennert-Cody 1999), suggesting that these largeamplitude waves may have been nonlinear, transporting water and plankton shoreward (Lamb 1997). Depending on the stratification, cross-shelf transport can be highly surface-enhanced (Lamb 1997), a process that might contribute to increased maximum relative fluorescence near the surface. Internal waves and internal tidal bores have been proposed as a mechanism for cross-shelf transport of planktonic organisms and nutrients (e.g. Shanks 1983, Kingsford \& Choat 1986, Leichter et al. 1996, Pineda 1991, 1999). However, preliminary analysis of fluorescence and beam c data collected while profiling at a near-surface drifter (Lennert-Cody 1999) show that similar patches form over wave troughs even in a quasi-Lagrangian sampling mode. For cross-shelf transport to be the only source of our observed pattern, there would have to be another mechanism frequently concentrating cells, or promoting increased biomass, offshore of the study site. Such a mechanism might take place at the shelf break in association with the internal tide (Kamykowski 1974, Sandstrom \& Elliott 1984).

Vertical mixing of organisms has been observed in breaking internal waves (Haury et al. 1983). We found no obvious indication of widespread wave breaking (i.e. obvious overturning) in our data. Rough estimates of the local Richardson number indicated that mixing in the upper part of the water column, if it were occurring, was most likely to have occurred in association with the largest waves on April 17 (Lennert-Cody 1999). However, maximum fluorescence associated with several of the largest waves on 17 April exceeded that through the water column just ahead of the waves, suggesting that patches of fluorescence within waves were not likely to be the result of local mixing. These observations do not exclude the possibility that wave breaking might have occurred offshore of our sampling station with the mixed waters transported shoreward by reformed waves (Lamb 1999) producing the observed fluorescence patchiness.

Our measurements show much less sub-surface patchiness of fluorescence in internal waves than would be inferred from surface observations. Observations of near-surface patchiness of phytoplankton likely associated with internal waves (e.g. Franks 1997 , C. E. Lennert-Cody pers. obs.) show concentrations that may be more than several times that of surrounding waters. However, we found patchiness to be at most $168 \%$ of the background concentration. This suggests that the near-surface dynamics of patch formation may be different from subsurface dynamics. Nonetheless, even at this magnitude, predictable subsurface phytoplankton patchiness in internal waves might have a range of implications for planktonic organisms. For species of dinoflagellate with the ability to reproduce sexually, the success of their sexual reproductive phase could be enhanced within these small-scale patches (Smayda 1997). This small-scale patchiness may also confer benefits to fast-swimming grazers, such as some copepods, with the ability to utilize ephemeral resources. Conversely, small-scale patchiness may lead to avoidance of concentrated toxic or noxious species (Carlsson et al. 1995).

In conclusion, we find that some characteristics of the observed fluorescence patchiness in highfrequency internal waves are consistent with model predictions of patchiness generated by swimming, particularly in spring, when blooms of dinoflagellates were present. However, comparison of fluorescence to beam c within waves suggests that changes in fluorescence yield are also occurring. Although we believe that swimming contributes to sub-surface patchiness of biomass in the presence of internal waves, this patchiness is less intense than that observed at the surface. We hypothesize that the relative contribution of swimming and non-photochemical quenching to variability in observed fluorescence depends on the phytoplankton community structure: blooms dominated by dinoflagellates will show swimming-related patches of 
enhanced biomass and fluorescence, as well as fluorescence yield, while the rest of the phytoplankton community will tend to show patches of enhanced fluorescence yield. Based on rough estimates of wave lengths of the larger-amplitude waves (Lennert-Cody 1999), we would expect these effects to be occurring on scales of hundreds of meters in the cross-shore direction, but possibly kilometers in the alongshore direction. This patchiness of swimming planktonic organisms in internal waves need not be limited to coastal environments. Swimming plankters in internal waves may form patches in the interior of the ocean due to the strain associated with the separation of isopycnals (cf. Rogachev et al. 1996, Kushnir et al. 1997). The presence of high-frequency internal waves associated with internal surges in lakes (Hunkins \& Fliegel 1973, Saggio \& Imberger 1998) suggests that this predictable patchiness might also be found in lakes.

Acknowledgements. The authors would like to extend special thanks to the many people who volunteered their time to make this field work possible: Renee Bender, Greg Cody, Jana Davis, Claudio DiBacco, Dave Fields, Karin Forney, Francisco, J. Shawn Houghtaling, Stacie Le, Andrew Leising, James Lerczak, Jessica McConnell, Rosana Petralia, Scott Rumsey, Mathias Saladin, Wendy Storms, Jenny Suter, Yuji Tanaka, Yuji's friend, and Mari Tashiro. The first author extends a very special thanks to Mari Tashiro, whose dedication and enthusiasm made this study possible. Charles Coughran, Ron McConnaughey, and Clinton Winant were invaluable resources throughout this study. Many thanks to James Pringle, James Lerczak and Myrl Hendershott for helpful discussions. The authors also thank Andy Visser, 2 anonymous reviewers and the Contributing Editor for constructive comments and suggestions that improved this manuscript. In particular, the authors wish to thank Andy Visser for pointing out that the swimming of vertical gradients in concentration cannot be ignored when studying concentration along isotherms.

\section{LITERATURE CITED}

Abbott MR, Richerson PJ, Powell TM (1982) In situ response of phytoplankton fluorescence to rapid variations in light. Limnol Oceanogr 27:218-225

Allen WE (1941) Twenty years' statistical studies of marine plankton dinoflagellates of southern California. Am Mid Nat 26:603-635

Baines PG (1986) Internal tides, internal waves and nearinertial motions. In: C Mooers (ed) Baroclinic processes on continental shelves. Coastal and Estuarine Sciences 3. American Geophysical Union, Washington, DC

Brockwell PJ, Davis RA (1987) Time series: theory and methods. Springer-Verlag, New York

Carlsson P, Granéli E, Finenko G, Maestrini SY (1995) Copepod grazing on a phytoplankton community containing the toxic dinoflagellate Dinophysis acuminata. J Plankton Res 17:1925-1938

Cleveland WS (1979) Robust locally weighted regression and smoothing scatterplots. J Am Stat Assoc 74:829-836

Cullen JJ, Lewis MR (1988) The kinetics of algal photoadap- tation in the context of vertical mixing. J Plankton Res 10 1039-1063

Cullen JJ, Stewart E, Renger E, Eppley RW, Winant CD (1983) Vertical motion of the thermocline, nitracline and chlorophyll maximum layers in relation to currents on the southern California Shelf. J Mar Res 41:239-262

Cullen JJ, Ciotti ÁM, Davis RF, Lewis MR (1997) Optical detection and assessment of algal blooms. Limnol Oceanogr 42:1223-1239

Demers S, Roy S, Gagon R, Vignault C (1991) Rapid lightinduced changes in cell fluorescence and in xanthophyllcycle pigments of Alexandrium excavatum (Dinophyceae) and Thalassiosira pseudonana (Bacillariophyceae): a photo-protection mechanism. Mar Ecol Prog Ser 76: 185-193

Denman KL (1976) Covariability of chlorophyll and temperature in the sea. Deep-Sea Res 23:539-550

Falkowski P, Keifer DA (1985) Chl a fluorescence in phytoplankton: relationship to photosynthesis and biomass. J Plankton Res 7:715-731

Franks PJS (1997) Spatial patterns in dense algal blooms. Limnol Oceanogr 42:1297-1305

Goodman D, Eppley RW, Reid FMH (1984) Summer phytoplankton assemblages and their environmental correlates in the Southern California Bight. J Mar Res 42: 1019-1049

Hastie TJ, Tibshirani RJ (1991) Generalized Additive Models. Monographs on Statistics and Applied Probability 43 Chapman \& Hall, London

Haury LR, Wiebe PH, Orr MH, Briscoe MG (1983) Tidally generated high-frequency wave packets and their effects on plankton in Massachusetts Bay. J Mar Res 41:65-112

Hunkins K, Fliegel M (1973) Internal undular surges in Seneca Lake: a natural occurrence of solitons. J Geophys Res 78:539-548

Kamykowski D (1973) Some physical and chemical aspects of phytoplankton ecology of La Jolla Bay. PhD thesis, University of California, San Diego

Kamykowski D (1974) Possible interactions between phytoplankton and semidiurnal internal tides. J Mar Res 32: $67-89$

Kamykowski D (1995) Trajectories of autotrophic marine dinoflagellates. J Phycol 31:200-208

Kamykowski D, Reed RE, Kirkpatrick GJ (1992) Comparison of sinking velocity, swimming velocity, rotation and path characteristics among six marine dinoflagellate species. Mar Biol 113:319-328

Kamykowski D, Milligan EJ, Reed RE (1998) Relationships between geotaxis/phototaxis and diel vertical migration in autotrophic dinoflagellates. J Plankton Res 20:1781-1796

Kiefer DA (1973) Chl a fluorescence in marine centric diatoms: responses of chloroplasts to light and nutrient stress. Mar Biol 23:39-46

Kingsford MJ, Choat JH (1986) Influence of surface slicks on the distribution and onshore movements of small fish. Mar Biol 91:161-171

Krause GH, Weis E (1991) Chlorophyll fluorescence and photosynthesis: the basics. Annu Rev Plant Physiol Plant Mol Biol 42:313-349

Kushnir VM, Tokarev YN, Williams R, Piontkovski SA, Evstigneev PV (1997) Spatial heterogeneity of the bioluminescence field of the tropical Atlantic Ocean and its relationship with internal waves. Mar Ecol Prog Ser 160: $1-11$

LaFond EC (1962) Internal waves. In: Hill MN (ed) The sea, Vol 1. Interscience Publishers, New York, p 731-751

LaFond EC (1965) The US Navy Electronics Laboratory's 
Oceanographic Research Tower: its developement and utilization. NEL Report 1342. Research and Development Report, December 22, 1965, San Diego, California

Lamb KG (1997) Particle transport by nonbreaking, solitary internal waves. J Geophys Res 102:18641-18660

Lamb KG (1999) Shoaling solitary internal waves and the formation of waves with trapped cores. EOS, Trans Am Geophys Union 80:215

Leichter JJ, Wing SR, Miller SL, Denny MW (1996) Pulsed delivery of subthermocline water to conch reef (Florida Keys) by internal tidal bores. Limnol Oceanogr 41: 1490-1501

Lennert-Cody CE (1999) Phytoplankton and high-frequency internal waves: predictable patchiness through the water column. PhD thesis, University of California, San Diego

Lennert-Cody CE, Franks PJS (1999) Plankton patchiness in high-frequency internal waves. Mar Ecol Prog Ser 186: 59-66

Lerczak JA (2000) Internal waves on the southern California shelf. PhD dissertation, University of California, San Diego

Lizon F, Lagadeuc Y, Brunet C, Aelbrecht D, Bentley D (1995) Primary production and photoadaptation of phytoplankton in relation with tidal mixing in coastal waters. J Plankton Res 17:1039-1055

Mackas DL (1984) Spatial autocorrelation of plankton community composition in a continental shelf ecosystem. Limnol Oceanogr 29:451-471

Moisan TA, Olaizola M, Mitchell BG (1998) Xanthophyll cycling in Phaeocystis antarctica: changes in cellular fluorescence. Mar Ecol Prog Ser 169:113-121

Olaizola M, La Roche J, Kobler Z, Falkowski PG (1994) Nonphotochemical fluorescence quenching and the diadinoxanthin cycle in a marine diatom. Photosynthesis Res 41: $357-370$

Pineda J (1991) Predictable upwelling and the shoreward transport of planktonic larvae by internal tidal bores. Science 253:548-551

Pineda J (1999) Circulation and larval distribution in internal tidal bore warm fronts. Limnol Oceanogr 44:1400-1414

Press WH, Flannery BP, Teukolsky SA, Vetterling WT (1989) Numerical recipes: the art of scientific computing (FORTRAN Version). Cambridge University Press, New York

Editorial responsibility: Thomas Kiørboe (Contributing Editor), Charlottenlund, Denmark
Rice JA (1988) Mathematical statistics and data analysis. Wadsworth and Brooks, Cole, Pacific Grove, California

Rogachev KA, Salomatin AS, Carmack EC (1996) Concentration of pelagic organisms at mesoscale fronts in the western subarctic Pacific: small fish on long waves. Fisheries Oceanography 5:153-162

Ryther JH (1955) Ecology of autotrophic marine dinoflagellates with reference to red water conditions. In: Johnson FH (ed) The luminescence of biological systems. American Association of the Advancement for Science, New York, p 387-413

Saggio A, Imberger J (1998) Internal wave weather in a stratified lake. Limnol Oceanogr 43:1780-1795

Sakshaug E, Demers S, Yentsch CM (1987) Thalassiosira oceanic and T. pseudonana: two different photoadaptational responses. Mar Ecol Prog Ser 41:275-282

Sandstrom H, Elliott JA (1984) Internal tide and solitons on the Scotian Shelf: a nutrient pump at work. J Geophys Res 89:6415-6426

Seber GFA (1984) Multivariate observations. John Wiley \& Sons, New York

Shanks AL (1983) Surface slicks associated with tidally forced internal waves may transport pelagic larvae of benthic invertebrates and fishes shoreward. Mar Ecol Prog Ser 13: 311-315

Smayda TJ (1997) Harmful algal blooms: their ecophysiology and general relevance to phytoplankton blooms in the sea. Limnol Oceanogr 42:1137-1153

Stramska M, Dickey T (1992) Short-term variations of the bio-optical properties of the ocean in response to cloudinduced irradiance fluctuations. J Geophys Res 97: 5713-5721

Stramski D, Kiefer DA (1991) Light scattering by microorganisms in the open ocean. Prog Oceanogr 28:343-383

Winant CD, Bratkovich AW (1981) Temperature and currents on the southern California shelf: a description of the variability. J Phys Oceanogr 11:71-86

Winant CD, Olson RJ (1976) The vertical structure of coastal currents. Deep-Sea Res 23:925-936

Zeldis JR, Jillett JB (1982) Aggregation of pelagic Mundia gregaria (Fabricius) (Decapoda, Anomura) by coastal fronts and internal waves. J Plankton Res 4:839-857

Submitted: March 29, 2001; Accepted: January 14, 2002 Proofs received from author(s): May 14, 2002 